Check for updates

Cite this: Chem. Commun., 2021, 57, 4055

Received 26th December 2020, Accepted 18th March 2021

DOI: $10.1039 / \mathrm{d} 0 \mathrm{cc} 08359 \mathrm{c}$

rsc.li/chemcomm

\section{Photocatalytic hydrogen production of porphyrin nanostructures: spheres vs. fibrils, a case study $\dagger$}

\author{
Vasilis Nikolaou, (D)* Georgios Charalambidis (D)* and \\ Athanassios G. Coutsolelos (D) *
}

\begin{abstract}
Herein, we illustrate the preparation of a covalent connected peptide-porphyrin hybrid (Fmoc-FF-(Zn)Por). The thorough investigation of its self-organization features demonstrated that Fmoc-FF(Zn)Por self-assembles into either spheres or fibrils by altering the solvent mixture. Interestingly, photocatalytic hydrogen $\left(\mathrm{H}_{2}\right)$ evolution experiments revealed that fibrils were more efficient towards $\mathrm{H}_{2}$ production compared to spheres.
\end{abstract}

In order to establish a sustainable and green future for our planet, we need to diminish the use of fossil fuels and rely on inexhaustible, clean and abundant energy sources. ${ }^{1,2}$ Thus, it is imperative to develop devices that effectively exploit solar energy into energy-rich and storable compounds that can be used as fuels. ${ }^{3}$ Hydrogen $\left(\mathrm{H}_{2}\right)$ is such a high-energy compound and is expected to become a major source of energy in the future. Among the wide variety of $\mathrm{H}_{2}$ generation approaches, photocatalytic water splitting is the most promising, due to it being cost effective and eco-friendly. Solar energy can be harnessed in media like water $\left(\mathrm{H}_{2} \mathrm{O}\right)^{4-6}$ and the aqueous protons can be converted into $\mathrm{H}_{2}$. Molecular hydrogen is considered as one of the most suitable solar fuels due to its high energy capacity and being environmental friendly. ${ }^{7}$ In contrast to hydrocarbons, the combustion of $\mathrm{H}_{2}$ produces only $\mathrm{H}_{2} \mathrm{O}$ as a by-product and can be utilized in any current natural gas system..$^{8-10}$ More importantly, the energy stored in $\mathrm{H}_{2}$ can be efficiently converted into electricity using fuel cells. ${ }^{11}$

For billion of years, nature through the process of photosynthesis efficiently converts solar irradiation into chemical energy. ${ }^{12}$ Motivated by natural photosynthesis, many scientific reports have been published over the years dealing with the direct conversion of sunlight into $\mathrm{H}_{2}{ }^{4,5,13}$ In natural photosynthesis the efficient and effective capture of solar energy is

Laboratory of Bioinorganic Chemistry, Department of Chemistry, University of Crete, Voutes Campus, 70013 Heraklion, Crete, Greece. E-mail:acoutsol@uoc.gr,gcharal@uoc.gr,v.nikolaou@uoc.gr

$\dagger$ Electronic supplementary information (ESI) available. See DOI: 10.1039/ d0cc08359c attributed to the well-organized structures of chlorophylls which are formed via their self-assembly. The exact orientation of porphyrinoids ensures an efficient stepwise energy transfer to the reaction center where charge separation occurs. ${ }^{14}$ The self-assembled chromophores have illustrated distinct properties compared to their initial monomer derivatives in many different scientific fields. ${ }^{15-19}$ There has been a prevalent interest in the preparation of self-assembled porphyrin nanostructures, aiming to imitate natural light harvesting processes in order to develop new nanostructured materials for photocatalytic processes. More specifically, self-assembled nanostructures have been used in photothermal therapy, ${ }^{16}$ in light harvesting applications ${ }^{17}$ and also as fluorescent probes and in data storage devices. ${ }^{20}$ In addition, self-assembled hybrids of magnetic and metal nanoparticles have been utilized in protein separation ${ }^{21}$ as well as the recovery of catalysts. ${ }^{22}$ Our research group has extensively studied the self-assembly of many different chromophores and systematically studied their photophysical and electrochemical features over the last 10 years. ${ }^{23-30}$ However, in the field of photocatalytic $\mathrm{H}_{2}$ evolution only a few reports dealing with $\mathrm{H}_{2}$ production upon the self-assembly of porphyrin chromophores are reported..$^{31-34}$ This approach though is very auspicious, since the self-assembled nanostructures have demonstrated superior catalytic activity due to their broad and enhanced absorption features. To the best of our knowledge, the impact of the different shapes of selfassembled nanostructures of the same hybrid has never been examined before. To that end, in this work we investigate the influence of two diverse nanostructures (spheres and fibrils) of the same porphyrin derivative in photocatalytic $\mathrm{H}_{2}$ evolution.

We synthesized a peptide-porphyrin hybrid (Fmoc-FF-(Zn)Por, Fig. 1) and investigated the self-assembly properties as well as the catalytic efficiency of the formed nanostructures with respect to their $\mathrm{H}_{2}$ evolution activity. Initially, the successful preparation of the non-metalated Fmoc-FF-Por derivative was performed following an already published procedure. ${ }^{29}$ The final step involved the metalation of the porphyrin macrocycle with zinc leading to the formation of Fmoc-FF-(Zn)Por (Scheme S1, ESI $\dagger$ ). All the 


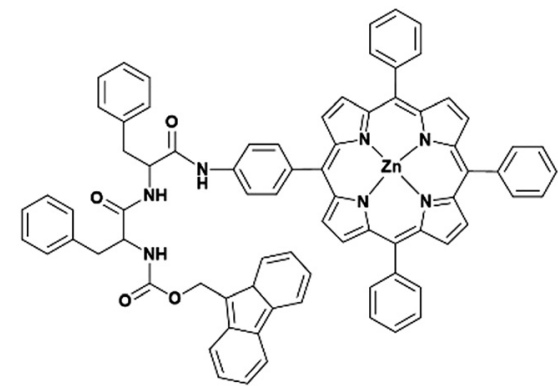

Fig. 1 The molecular structure of the studied porphyrin-peptide hybrid (Fmoc-FF-(Zn)Por).

experimental details regarding the preparation as well as the characterization of Fmoc-FF-(Zn)Por are provided in the ESI. $\dagger$ Furthermore, the ${ }^{1} \mathrm{H}$ and ${ }^{13} \mathrm{C}$ NMR spectra of the hybrid are illustrated in Fig. S1-S3 (ESI $\dagger$ ).

In order to investigate the self-assembly features of FmocFF-(Zn)Por, scanning electron microscopy (SEM) was utilized. For the successful formation of the self-assembled structures, the "good-bad" solvent methodology was applied. ${ }^{25}$ As illustrated in Fig. 2, Fmoc-FF-(Zn)Por can self-assemble into spheres or fibrils by utilizing different solvent mixtures. Nanosphere formation (Fig. 2a) occurs when Fmoc-FF-(Zn)Por is dissolved in tetrahydrofuran (THF) and thereupon diluted in a polar solvent such as methanol (MeOH) (THF/MeOH, $2: 8$ ratio, $1 \mathrm{mM}$ ). Howbeit, when dichloromethane/heptane solvent mixture (DCM/HEPT, 1:1 ratio, $1 \mathrm{mM}$ ) was employed, the formation of micrometre long fibrils instead of nanospheres was observed (Fig. 2b). Thus, by altering the solvent mixture, the same compound self-assembles into two distinctive nanostructures. Depending on the kinetic conditions and the type of surfactants, the resulting structures exhibit well-defined one to three dimensional morphologies.

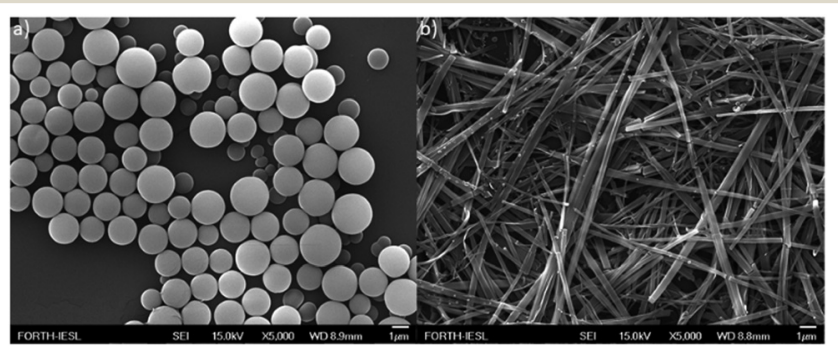

Fig. 2 The diverse self-assembly of Fmoc-FF-(Zn)Por: (a) spheres and (b) fibrils.

Similar self-assembling studies on the non-metallated Fmoc-FF-Por hybrid have already been reported by our research group. ${ }^{29,30}$ In the case of Fmoc-FF-Por by simply changing the ratio of the "good-bad" solvent mixture we were able to form either spherical or fibrilar nanostructures (Fig. S4, ESI $\dagger$ ). However, by using the same conditions, the formation of spherical nano-assemblies was not observed in Fmoc-FF-Zn(Por). In particular, in DCM/HEPT (1:1 ratio), Fmoc-FF-Por formed spherical nanostructures, whereas Fmoc-FF-Zn(Por) formed fiblils. Therefore, the presence of the $\mathrm{Zn}$ metal in the porphyrin ring strongly affects the self-assembling properties of the hybrid.

The photophysical features of Fmoc-FF-(Zn)Por in solution and in the solid state were investigated and more importantly, a comparison was performed between the spherical and fibrilar nanostructures (Fig. 3). Typical absorption features of a zincmetallated porphyrin derivative were observed in the spectrum of Fmoc-FF-(Zn)Por in THF (green line). Namely, a Soret band at $424 \mathrm{~nm}$ and two additional absorption peaks at 556 and $596 \mathrm{~nm}$ (Q-bands). The absorption features in the amorphous solid state were slightly broadened though and the Q-bands at 560 and $601 \mathrm{~nm}$ (red line) were red-shifted. Concerning the self-assembled nanostructures, both spherical and fiblrilar assemblies (black and blue line, respectively) lead to broader absorption features compared to the solid and the solution spectra. Apart from the wide broadening of all absorption peaks, we also observed a red-shift in the peaks of the Q-region. Overall, upon the self-assembly of Fmoc-FF-(Zn)Por into fibrils and spheres its absorption range was significantly enlarged, leading to enhanced solar irradiation harvesting; a highly desirable feature in artificial photosynthesis concepts.

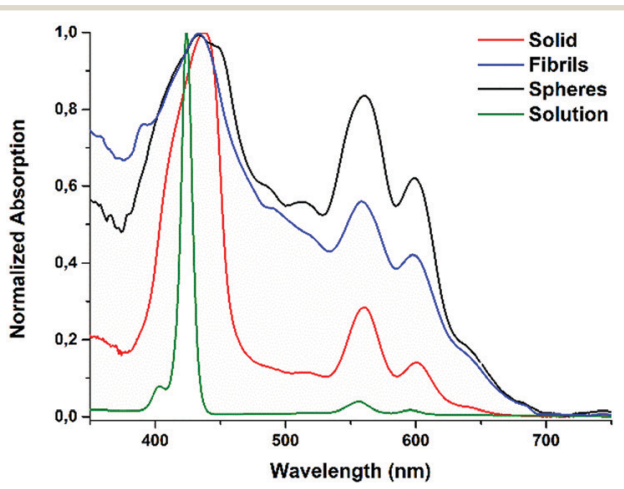

Fig. 3 Absorption spectra of Fmoc-FF-(Zn)Por in the solid state, in solution and upon its self-assembly into spheres or fibrils.

The emission characteristics of Fmoc-FF-(ZnPor) were also examined through fluorescence spectroscopy. The fluorescence features of the hybrid were evaluated upon preparing samples in solution, in the solid state as well as in spherical or fibrilar conformations (Fig. 4). In solution, two emission peaks were detected at 606 and $655 \mathrm{~nm}$ (green line). Similarly, in the solid sample two emission peaks were also noticed (red line), although the first one was slightly red-shifted at $609 \mathrm{~nm}$. A completely different behaviour was observed in the emission spectra of the self-assembled samples (fibrils or spheres). In particular, the relative intensity of the two emission peaks was altered compared to the corresponding solid and solution samples. It is worth mentioning that in the self-assembled samples the second emission peak is greater compared to the first. Time-resolved fluorescence lifetime measurements were also performed (Fig. S5, ESI $\dagger$ ). In THF solution, Fmoc-FF(ZnPor) revealed a fluorescence lifetime $(\tau)$ of $1.8 \mathrm{~ns}$, while the self-assembling nanostructures presented significantly reduced values $\left(\tau_{\text {spheres }}=0.48 \mathrm{~ns}\right.$ and $\left.\tau_{\text {fibrils }}=0.58 \mathrm{~ns}\right)$. Notably, 
the amorphous solid sample displayed the lowest lifetime, namely $\tau_{\text {solid }}=0.41$ ns. Hence, the self-assembly process reduces the lifetime of the singlet excited state. The short lifetimes of the nanostructures compared to the solution are a result of a quenching process due to intermolecular interactions between the porphyrin units. All of the above results highlight that self-organization altered the features of Fmoc-FF(ZnPor) not only in the ground state (absorption studies) but in the excited state as well (emission studies).

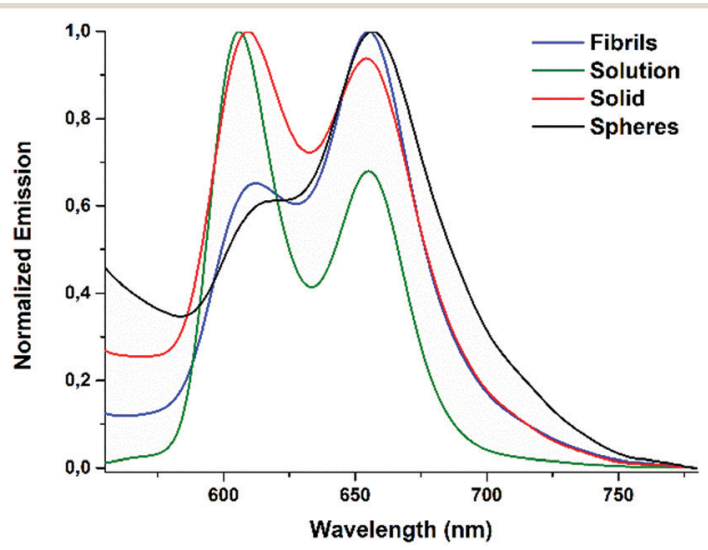

Fig. 4 Emission spectra of Fmoc-FF-(Zn)Por in the solid state, in solution and upon its self-assembly into spheres or fibrils.

Consequently, the catalytic performance of the selfassembled Fmoc-FF-(ZnPor) hybrids was evaluated by conducting photo-induced hydrogen $\left(\mathrm{H}_{2}\right)$ production experiments. The spherical and the fibrilar nanostructures were utilized as photocatalysts upon the photo-deposition of Pt nanoparticles (using $\mathrm{Na}_{2} \mathrm{PtCl}_{6}$ as a platinum source, see the ESI $\dagger$ ). For comparison reasons the catalytic activity of the amorphous solid sample was also examined. The photocatalytic experiments were performed in aqueous solutions containing $1.0 \mathrm{M}$ of ascorbic acid (AA) as a sacrificial electron donor ( $\mathrm{SED}$ ), at $\mathrm{pH}=4$. In Fig. 5, the $\mathrm{H}_{2}$ production plots of the solid, as well as the spherical and the fibrilar nano-assemblies are illustrated.

The fibrilar nanostructures of Fmoc-FF-(Zn)Por presented the highest catalytic performance with a maximum $\mathrm{H}_{2}$ evolution rate of $1.96 \mathrm{mmol} \mathrm{g}^{-1} \mathrm{~h}^{-1}$ (Fig. S6, ESI $\dagger$ ). Hence, the fibrils constitute a very stable catalytic system which remains active for more than 400 hours, exhibiting a maximum TON of 155 (vs. Pt catalyst) after 406 hours of irradiation. In stark contrast, the spherical nanostructures displayed negligible photocatalytic activity, demonstrating only 10 TONs after 360 hours of irradiation. Furthermore, the catalytic efficiency of the amorphous solid sample is slightly higher compared to the spherical nanostructures, but still considerably lower than the fibrilar nano-assemblies, demonstrating 17 TONs after 378 hours. These results point out that the self-assembly of Fmoc-FF(ZnPor) into fibrils is essential towards enhancing the photocatalytic efficiency. Firstly, the light absorption features of Fmoc-FF-(ZnPor) were increased due to the highly ordered molecular assembly of the aggregated nanostructures as

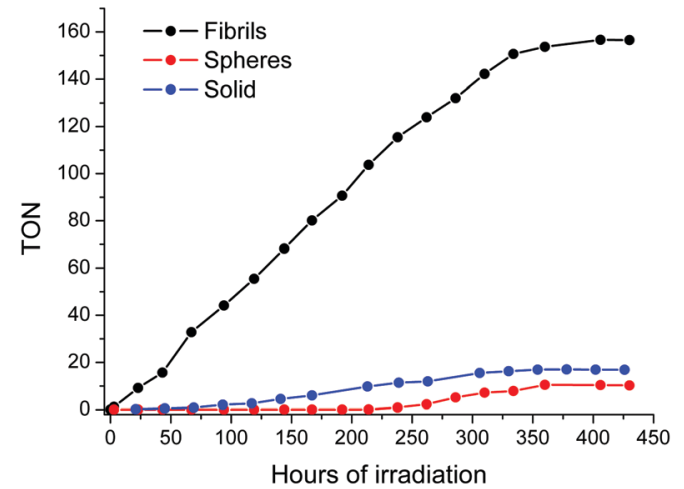

Fig. $5 \quad \mathrm{H}_{2}$ evolution plots of Fmoc-FF-(Zn)Por upon its self-assembly into spheres (red line), fibrils (black line) and solids (blue line). All the results presented in the $\mathrm{H}_{2}$ production plots are the average value of three independent measurements.

presented in the absorption spectra (Fig. 5). Moreover, the one-dimensional nanostructures (fibrils) undergo delocalization phenomena and more importantly reduce the charge recombination processes. ${ }^{34,35}$ Thus, the products from electron transfer are stabilized more effectively and the lifetime of the electron-hole pair is increased. ${ }^{34,35}$

In order to determine the pathway that leads to the deactivation of the photocatalytic system we performed additional SEM studies for the fibrilar and spherical nanostructures. More specifically, upon the completion of the photocatalytic measurements, SEM studies were conducted in order to compare the morphology of the self-assembled nanostructures before and after the catalytic process. Interestingly, the spherical nanostructures retained their morphology at a great point in contrast to the fibrils which were completely destroyed (Fig. 6). In great accordance with the $\mathrm{H}_{2}$ evolution results, the fibrils were catalytically active until their morphology was retained. As the SEM examination indicates, their morphology was destroyed after 430 hours of irradiation leading to the diminishing of $\mathrm{H}_{2}$ production.

In an effort to determine if the molecular structure of Fmoc-FF-(Zn)Por has changed upon the completion of the photocatalysis, we performed additional absorption, emission and mass spectrometry studies. All the recorded spectra (Fig. S7-S10, ESI $\dagger$ ) indicate that the continuous light irradiation is not altering either the structure or the properties of the hybrid. These results reveal that the "used" Fmoc-FF-(Zn)Por

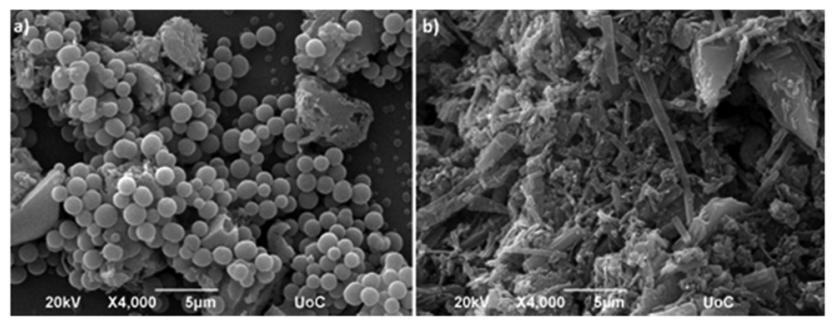

Fig. 6 The SEM images of Fmoc-FF-(Zn)Por nanostructures after the photocatalysis: (a) spheres and (b) fibrils (damaged). 
sample can be recycled and used again in photocatalytic experiments.

In conclusion, two well defined nanostructures (spheres and fibrils) of Fmoc-FF-(Zn)Por were examined as photocatalysts in $\mathrm{H}_{2}$ production. According to our results, two distinctive forms of the same hybrid, presented different catalytic activities towards $\mathrm{H}_{2}$ production. The latter verifies that the shape of self-assembly controls $\mathrm{H}_{2}$ production, since fibrils were more efficient compared to spheres or to the amorphous solid. Overall, in our work the fibrilar nanostructures demonstrated photocatalytic stability for more than 400 hours with a maximum $\mathrm{H}_{2}$ evolution rate of $1.96 \mathrm{mmol} \mathrm{g}^{-1} \mathrm{~h}^{-1}$ and a maximum TON of 155. Based on these values, the nanostructures presented herein could be considered among the most efficient examples in the literature (Table S1, ESI $\dagger$ ) considering that the self-organization of a molecule (photosensitizer or catalyst) is studied. Benefiting from the results of this work, novel devices could be developed that utilize self-assembled nanostructures of controlled shape, targeting high efficiency and increased stability. The catalytic performance of similar hybrids could be enhanced by altering the peripheral substituents of the porphyrin ring and this approach would be helpful to improve the light-assisted $\mathrm{H}_{2}$ evolution of porphyrinbased systems.

This research was financed by Greece and the European Union (European Social Fund-ESF) through the Operational Programme "Human Resources Development, Education and Lifelong Learning 2014-2020" in the project "Photocatalytic $\mathrm{H}_{2}$ production and $\mathrm{CO}_{2}$ reduction using self-assembled chromophorecatalyst nanostructures" (MIS 5048472).

\section{Conflicts of interest}

There are no conflicts to declare.

\section{Notes and references}

1 C.-M. Fung, J.-Y. Tang, L.-L. Tan, A. R. Mohamed and S.-P. Chai, Mater. Today Sustainability, 2020, 9, 100037.

2 H. P. Le and S. A. Sarkodie, Energy Rep., 2020, 6, 965.

3 A. Mustafa, B. G. Lougou, Y. Shuai, Z. Wang and H. Tan, J. Energy Chem., 2020, 49, 96.

4 Y. Liu, D. Huang, M. Cheng, Z. Liu, C. Lai, C. Zhang, C. Zhou, W. Xiong, L. Qin, B. Shao and Q. Liang, Coord. Chem. Rev., 2020, 409, 213220.

5 T. Hisatomi and K. Domen, Nat. Catal., 2019, 2, 387.

6 J. Cai, J. Shen, X. Zhang, Y. H. Ng, J. Huang, W. Guo, C. Lin and Y. Lai, Small Methods, 2019, 3, 1800184.

7 D. Dolui, S. Ghorai and A. Dutta, Coord. Chem. Rev., 2020, 416, 213335.

8 S. K. Saraswat, D. D. Rodene and R. B. Gupta, Renewable Sustainable Energy Rev., 2018, 89, 228.

9 J. Willkomm, K. L. Orchard, A. Reynal, E. Pastor, J. R. Durrant and E. Reisner, Chem. Soc. Rev., 2016, 45, 9.

10 J. R. Swierk and T. E. Mallouk, Chem. Soc. Rev., 2013, 42, 2357.
11 I. Staffell, D. Scamman, A. Velazquez Abad, P. Balcombe, P. E. Dodds, P. Ekins, N. Shah and K. R. Ward, Energy Environ. Sci., 2019, 12, 463.

12 A. Magnuson, F. Mamedov and J. Messinger, Joule, 2020, 4, 1157.

13 K. C. Christoforidis and P. Fornasiero, ChemCatChem, 2017, 9, 1523.

14 J. Z. Zhang and E. Reisner, Nat. Rev. Chem., 2020, 4, 6.

15 M.-Y. Yeh, T.-Y. Tseng, H.-C. Hsieh, B.-X. Wu, Y.-S. Liao, Y.-C. Yeh and J.-C. Liu, ChemPhotoChem, 2020, 4, 481.

16 Y. Liu, H. Wang, S. Li, C. Chen, L. Xu, P. Huang, F. Liu, Y. Su, M. Qi, C. Yu and Y. Zhou, Nat. Commun., 2020, 11, 1724.

17 M. Kownacki, S. M. Langenegger, S.-X. Liu and R. Häner, Angew. Chem., Int. Ed., 2019, 58, 751.

18 V. Gadenne, B. Grenier, C. Praveen, P. Marsal, J. C. Valmalette, L. Patrone and J. M. Raimundo, Phys. Chem. Chem. Phys., 2019, 21, 25865.

19 D. A. Hinton, J. D. Ng, J. Sun, S. Lee, S. K. Saikin, J. Logsdon, D. S. White, A. N. Marquard, A. C. Cavell, V. K. Krasecki, K. A. Knapper, K. M. Lupo, M. R. Wasielewski, A. Aspuru-Guzik, J. S. Biteen, P. Gopalan and R. H. Goldsmith, J. Am. Chem. Soc., 2018, 140, 15827.

20 Z. Nie, A. Petukhova and E. Kumacheva, Nat. Nanotechnol., 2010, $5,15$.

21 J. J. McManus, P. Charbonneau, E. Zaccarelli and N. Asherie, Curr. Opin. Colloid Interface Sci., 2016, 22, 73.

22 M. Mohan, N. Mohan and D. K. Chand, J. Mater. Chem. A, 2015, 3, 21167.

23 E. Nikoloudakis, K. Mitropoulou, G. Landrou, G. Charalambidis, V. Nikolaou, A. Mitraki and A. G. Coutsolelos, Chem. Commun., 2019, 55, 14103.

24 E. Nikoloudakis, K. Karikis, J. J. Han, C. Kokotidou, A. Charisiadis, F. Folias, A. M. Douvas, A. Mitraki, G. Charalambidis, X. H. Yan and A. G. Coutsolelos, Nanoscale, 2019, 11, 3557.

25 K. Karikis, A. Butkiewicz, F. Folias, G. Charalambidis, C. Kokotidou, A. Charisiadis, V. Nikolaou, E. Nikoloudakis, J. Frelek, A. Mitraki and A. G. Coutsolelos, Nanoscale, 2018, 10, 1735.

26 G. Charalambidis, K. Karikis, E. Georgilis, B. L. M'Sabah, Y. Pellegrin, A. Planchat, B. Lucas, A. Mitraki, J. Boucle, F. Odobel and A. G. Coutsolelos, Sustainable Energy Fuels, 2017, 1, 387.

27 E. Nikoloudakis, K. Karikis, M. Laurans, C. Kokotidou, A. SoleDaura, J. J. Carbo, A. Charisiadis, G. Charalambidis, G. Izzet, A. Mitraki, A. M. Douvas, J. M. Poblet, A. Proust and A. G. Coutsolelos, Dalton Trans., 2018, 47, 6304.

28 K. Karikis, E. Georgilis, G. Charalambidis, A. Petrou, O. Vakuliuk, T. Chatziioannou, I. Raptaki, S. Tsovola, I. Papakyriacou, A. Mitraki, D. T. Gryko and A. G. Coutsolelos, Chem. - Eur. J., 2016, 22, 11245.

29 G. Charalambidis, E. Georgilis, M. K. Panda, C. E. Anson, A. K. Powell, S. Doyle, D. Moss, T. Jochum, P. N. Horton, S. J. Coles, M. Linares, D. Beljonne, J. V. Naubron, J. Conradt, H. Kalt, A. Mitraki, A. G. Coutsolelos and T. S. Balaban, Nat. Commun., 2016, 7, 12657.

30 G. Charalambidis, E. Kasotakis, T. Lazarides, A. Mitraki and A. G. Coutsolelos, Chem. - Eur. J., 2011, 17, 7213.

31 N. Zhang, L. Wang, H. Wang, R. Cao, J. Wang, F. Bai and H. Fan, Nano Lett., 2018, 18, 560.

32 G. B. Bodedla, L. Li, Y. Che, Y. Jiang, J. Huang, J. Zhao and X. Zhu, Chem. Commun., 2018, 54, 11614.

33 G. B. Bodedla, J. Huang, W.-Y. Wong and X. Zhu, ACS Appl. Nano Mater., 2020, 3, 7040 .

34 J. Wang, Y. Zhong, L. Wang, N. Zhang, R. Cao, K. Bian, L. Alarid, R. E. Haddad, F. Bai and H. Fan, Nano Lett., 2016, 16, 6523.

35 J. H. Kim, M. Lee, J. S. Lee and C. B. Park, Angew. Chem., Int. Ed., 2012, 51, 517. 